\title{
Photoperiod-induced differential expression of angiogenesis genes in testes of adult Peromyscus leucopus
}

\author{
Leah M Pyter, Andrew K Hotchkiss and Randy J Nelson \\ Departments of Neuroscience and Psychology, Ohio State University, Columbus, OH 43210, USA \\ Correspondence should be addressed to L M Pyter; Email: pyter.1@osu.edu
}

\begin{abstract}
Non-pathological angiogenesis in adults is rare and is largely thought to be restricted to wound healing and female reproductive cycles. Adult male rodents, however, display seasonal angiogenesis to support seasonal changes in reproductive tissue morphology. Non-tropical rodents use photoperiod (day length) to determine the time of year. During short days, the reproductive system undergoes involution and mating behaviours stop, adaptations which presumably allow energy resources to be shifted to processes necessary for winter survival. We compared the patterns of gene expression involved in angiogenesis in testes of white-footed mice (Peromyscus leucopus) following 7, 14, 21 or 34 weeks of long or short day lengths. Short days decreased body mass, reproductive tract mass and seminiferous tubule diameter. Potential genes involved in seasonal angiogenesis were screened by hybridizing testicular RNA from each group to angiogenesis-specific microarrays. Genes that were $\geq 6$-fold different between long- and short-day testes (i.e. hypoxia-inducible factor $1 \alpha$ (Hif1 $\alpha$ ), plasminogen activator inhibitor 1 (Serpine1), transforming growth factor $\beta$ receptor $3(\operatorname{Tgf} \beta r 3)$ and tumour necrosis factor $(\operatorname{Tnf}))$ were sequenced and expression differences were compared throughout gonadal regression and recrudescence using quantitative RT-PCR. Our results suggest that short days trigger expression of Hif1 $\alpha$, Serpine1, and $\operatorname{Tgf\beta r} 3$ to inhibit angiogenesis or promote apoptosis during testicular regression, and also trigger expression of $\mathrm{Tnf}$ to promote angiogenesis during testicular recrudescence.

Reproduction (2005) 129 201-209
\end{abstract}

\section{Introduction}

Angiogenesis is the process by which new blood vessels are formed from existing vessels. In adult mammals, angiogenesis is principally confined to the processes of wound healing, tumorigenesis and physiological changes associated with female reproductive cycles (Tomanek \& Schatteman 2000, Smith 2001). Some evidence suggests, however, that adult male reproductive tissues are also capable of angiogenesis. Rodents residing in environments that undergo dramatic seasonal changes display marked morphological changes in order to adapt to the fluctuating environment (Bronson 1985). These rodents often use photoperiod (day length) for temporal information to initiate and terminate seasonally appropriate morphological, physiological and behavioural adaptations that maximize survival and reproductive success (Prendergast et al. 2001). Short day lengths trigger regression of the reproductive tract and cessation of reproductive behaviours in many rodents, an adaptation thought to shift energy reserves to survival functions (Nelson et al. 2002). Regrowth of the reproductive tract commences after prolonged exposure to short day lengths so that full reproductive development precedes the onset of the mating season
(Gram et al. 1982). In the laboratory, seasonal changes can be triggered in many seasonally responsive rodents solely by manipulation of photoperiod (Smale et al. 1988, Prendergast \& Nelson 2001); photoperiod information is transduced into a physiological signal via the pineal hormone, melatonin (Goldman 2001).

The mass of the reproductive tract of male whitefooted mice (Peromyscus leucopus) decreases following 6-12 weeks of exposure to short photoperiods (Lynch et al. 1981). Testicular cells (primarily spermatids and spermatocytes) undergo apoptosis in short days, which may contribute to decreased tissue mass (Young et al. 2000, Young \& Nelson 2001). Seasonal changes in testicular capillary blood flow (Joffre \& Joffre 1973), permeability of the blood-testis barrier (Pelletier 1986), and volume and density of testicular microvasculature (Mayerhofer et al. 1989) have been reported in several species that breed seasonally. The molecular mechanisms that regulate vascular development and demolition in response to environmental cues remain unspecified. However, the collapse and regrowth of the testes positively correlates with vascular endothelial growth factor (VEGF) protein expression (Young \& Nelson 2000). VEGF 
is a growth factor that is present during blood vessel growth of tumours, wound healing and uterine vascularization (Neufeld et al. 1999).

The photoperiod-driven cycle of VEGF protein levels in the testes of white-footed mice is evidence that changes in tissue mass may be accompanied by changes in the supporting vasculature. Tissue growth may precede growth of the vascular bed and tissue demise may precede vascular regression or vice versa. For example, excessive tumour growth can be inhibited by prevention of angiogenesis suggesting that tissue growth precedes angiogenesis (Brem 1976). However, seasonal changes in testicular blood vessel volume precede measurable changes in testes morphology in Syrian hamsters (Mesocricetus auratus), suggesting that angiogenesis precedes tissue morphology (Mayerhofer et al. 1989). Also, a seasonal increase in testicular blood flow precedes the presence of spermatozoa in testes of dormice (Glis glis), but not ferrets (Mustello furo) and foxes (Vulpes vulpes) (Joffre \& Joffre 1973). Regardless of the timing of angiogenesis, the process consists of four main steps: (1) degradation of the epithelial layer of the existing vessel by matrix metalloproteinases; (2) recruitment of growth factors; (3) proliferation and recruitment of new epithelial cells; (4) stabilization of the new vessel by smooth muscle cells (Klagsbrun \& Moses 1999). To maintain vasculature, many blood-borne factors are involved and are expressed in a balance between promoting and inhibiting angiogenesis (Klagsbrun \& Moses 1999). When the signal to expand the vasculature is initiated, this balance swings in favour of the pro-angiogenic factors. We hypothesized that expression of angiogenesis genes would differ in the testes between long- and short-photoperiod-treated white-footed mice and that these differences would correspond to the pattern of testicular regression and regrowth.

\section{Materials and Methods}

\section{Animals}

White-footed mice ( $P$. leucopus) from our breeding colony were used in this study (116 adult males; $>55$ days of age). Animals were housed individually in polypropylene cages $(27.8 \times 7.5 \times 13 \mathrm{~cm})$ with a constant temperature and humidity of $21 \pm 5{ }^{\circ} \mathrm{C}$ and $50 \pm 5 \%$ respectively; food (Harlan Teklad 8640 rodent diet, Indianapolis, IN, USA) and filtered tap water were available ad libitum. Mice were either housed in a reverse long (16 h light per day; lights illuminated at $2300 \mathrm{~h}$ Eastern Standard Time $(\mathrm{EST})$ ) photoperiod $(n=36)$, or in a short ( $8 \mathrm{~h}$ light per day ; lights illuminated at $0700 \mathrm{~h}$ ) photoperiod ( $n=80$ males). Mice exposed to short days that failed to regress their reproductive tract (approximately 35\%) were included in the study as a separate group described below as 'shortday, non-responsive' mice. Mice were maintained in their respective photoperiods for 7, 14, 21 or 34 weeks. All studies were conducted after approval by the Ohio State
University Institutional Animal Care and Use Committee and were in compliance with all US federal animal welfare requirements.

\section{Experimental procedures}

Body mass and reproductive responses to photoperiod were assessed bi-weekly under light isoflurane anaesthetization. Reproductive status was assessed by external measurement of the left testis with calipers. The product of testis length times testis width squared provides a measure of estimated testis volume (ETV) that is highly correlated with testis weight (Gorman \& Zucker 1995). After 7, 14, 21 and 34 weeks of photoperiod treatment, 4-34 male mice (from each photoperiod) were killed via rapid cervical dislocation and tissues were collected.

\section{Tissue collection}

Right testis, epididymides, epididymal fat pads and seminal vesicles were collected from mice under aseptic conditions and submerged in 10 volumes $(10 \mu \mathrm{l}$ per $\mathrm{mg}$ tissue) of RNALater RNA stabilization reagent (Qiagen) and stored at $4{ }^{\circ} \mathrm{C}$ for $24 \mathrm{~h}$. All surgical instruments were washed consecutively with 70\% alcohol, RNAse Away (Fisher, Pittsburgh, PA, USA) and sterile deionized water between mice. Seminal vesicle fluid was expressed prior to storage. Following $24 \mathrm{~h}$ of RNALater submergence, tissues were blotted briefly, weighed and frozen at $-70^{\circ} \mathrm{C}$ until RNA processing. Prior to weighing, connective tissue and fat were cleaned from epididymides. The left testis was collected from each mouse and fixed in $10 \%$ neutral buffered formalin for at least 2 weeks until processed for histology. The mean testes mass for long-day (LD) mice was determined and all short-day (SD) males with testes mass equal to or greater than 1.5 standard deviations below this mean were considered reproductively responsive to short days (SDR), whereas those mice that did not differ from the LD mean were considered non-responsive to short days (SDNR).

\section{Histology}

Testes were fixed in $10 \%$ neutral buffered saline, paraffin embedded and cut into $5 \mu \mathrm{m}$ sections on a rotary microtome. Sections were progressively stained with eosin $Y$ and Harris haematoxylin, and coverslips were affixed with Permount. Diameters of 10 seminal vesicles chosen semirandomly using a fixed line across the section were visualized with light microscopy at $\times 20$ or $\times 30$ power and measured on five randomly selected sections of each testes using SpotBasic software (Diagnostic Instruments, Inc., Sterling Heights, MI, USA). Diameters were measured only if their length and width differed by $<25 \%$. Seminiferous tubule measurements of SDNR mice at 21 weeks were excluded due to improper embedding processing. 


\section{RNA extraction}

Total RNA was extracted from $\leq 30 \mathrm{mg}$ of individual testes using a rotor-stator homogenizer with an RNeasy Mini Kit according to the manufacturer's protocol (Qiagen). Extracted RNA was suspended in 30-50 $\mu$ l RNase-free water and RNA concentration was determined by spectrophotometer. For gene array analysis, aliquots of equal mass (e.g. $1 \mu \mathrm{g}$ ) from individual RNA samples at the 14week time point were pooled to create a single pooled sample representative of each photoperiod treatment group. Individual samples with concentrations $<100 \mu \mathrm{g} / \mathrm{ml}$ were excluded from the pooled sample $(n=1, \mathrm{LD}$ at week 21). For quantitative PCR (qPCR), individual RNA samples were used. All RNA samples were stored at $-80^{\circ} \mathrm{C}$ until gene expression analysis.

\section{Microarrays}

As a preliminary screen for differences in angiogenesis gene expression, microarrays were hybridized with testicular RNA after 14 weeks of photoperiod treatment. Non-Radioactive Mouse Angiogenesis GEArray Q Series microarrays with the GEArray RT-labeling method (SuperArray, Frederick, MD, USA) were used according to the manufacturer's protocol with a few modifications. Briefly, $4 \mu \mathrm{g}$ of each pooled RNA sample were reverse transcribed to CDNA and used for probe synthesis and the reverse transcription step was extended to $4 \mathrm{~h}$. Hybridization of labeled cDNA to the microarray occurred at $59^{\circ} \mathrm{C}$ for $24 \mathrm{~h}$. On a sheet of plastic wrap, the chemiluminescent substrate was incubated on the array for $4 \mathrm{~min}$ while covered by a piece of Parafilm (Fisher) to equalize the substrate distribution. Immediate, side-by-side chemiluminescent imaging of the microarray from each treatment was made possible by a CCD camera imaging system and detection was stopped upon pixel saturation. Quantity One software (Applied Biosystems, Foster City, CA, USA) was used to capture images and measure relative density of gene spots after background subtraction. Individual gene spot density was quantified following normalization to the density of the Gapdh spot. We plotted the distribution of the fold differences in gene expression against the number of genes and designated a cut-off point based on the mean fold difference (mean $=5.7$ ). Therefore, genes with expression levels that differed $\geq 6$-fold among treatment groups were examined throughout testicular regression and recrudescence via qPCR.

\section{Sequencing}

In order to design species-specific primers and probes for qPCR, a portion of each gene of interest was sequenced. Semi-degenerate primers were designed based on conserved regions between Mus musculus and Rattus norvegicus gene sequences using PrimerExpress software (Applied Biosystems; Table 1). Forty cycles of PCR were conducted on $1 \mu \mathrm{l}$ cDNA from pooled $P$. leucopus RNA with Taq DNA Polymerase enzyme (Invitrogen), according to the manufacturer's protocol, in a thermocycler with melting temperatures of $59-60{ }^{\circ} \mathrm{C}$. Gene-product amplification was visualized on $2 \% 40 \mathrm{mM}$ Tris acetate and $2 \mathrm{mM}$ ETDA (TAE)-agarose gels containing ethidium bromide using a CCD camera. To verify amplification of the correct gene, PCR products of the expected molecular size were purified (Centricon-100, Millipore, Billerica, MA, USA), and sequenced at the Plant-Genomics Centre at Ohio State University. Resulting amplicon sequences were $>90 \%$ homologous to the Mus gene of interest and therefore were assumed to be the correct $P$. leucopus gene of interest.

\section{Quantitative RT-PCR}

We examined and quantified potentially functional gene expression differences of hypoxia-inducible factor $1 \alpha$ $($ Hif $1 \alpha)$, transforming growth factor $\beta$ receptor 3 (Tgf $\beta r 3)$, plasminogen activator inhibitor 1 (Serpine1) and tumour necrosis factor (Tnf) using qPCR. Expression of these genes was quantified for individual animals of each photoperiod group at all four time points in duplicate or triplicate. Individual RNA samples $(n=4$ per photoperiod group per time point) were reverse transcribed into cDNA with MMLV Reverse Transcriptase enzyme (Invitrogen) according to the manufacturer's protocol. Primers and probes for qPCR were designed based on the attained sequencing information using PrimerExpress. Primers and probes were synthesized as follows, with probes labeled with 6-FAM

Table 1 Sequencing information for genes differentially expressed $\geq 6$-fold in microarray analysis.

\begin{tabular}{|c|c|c|c|}
\hline Gene & Primer sequences for sequencing & $\mathrm{Tm}$ & Accession number created \\
\hline Hypoxia-inducible factor $1 \alpha($ Hif $1 \alpha)$ & $\begin{array}{l}\text { Forward: AGAAACCRCCYATGACGTGC } \\
\text { Reverse: CCACCTCTTTTKGCAAGCAT }\end{array}$ & 60 & AY591916 \\
\hline Plasminogen activator inhibitor 1 (Serpine1) & $\begin{array}{l}\text { Forward: ACRTCSTGGAACTGCCCTAC } \\
\text { Reverse: GAGCTGCTCTTGGTCGAAA }\end{array}$ & 60 & AY591915 \\
\hline Transforming growth factor $\beta$ receptor 3 (Tgf $\beta r 3$ ) & $\begin{array}{l}\text { Forward: GCACCAGGAAGAGGTCTGTGTT } \\
\text { Reverse: ATGGCTTTGAAGACATGGAGTCA }\end{array}$ & 59 & AY591914 \\
\hline Tumor necrosis factor (Tnf) & $\begin{array}{l}\text { Forward: GGAGGCACTCCCCAAAAAG } \\
\text { Reverse: AGCCTTGGCCCTTGAAGAG }\end{array}$ & 59 & AY608911 \\
\hline $18 S r R N A$ & $\begin{array}{l}\text { Forward: CACGGCCGGTACAGTGAAAC } \\
\text { Reverse: AGTTGATAGGGCAGACGTTCGA }\end{array}$ & 60 & AY591913 \\
\hline
\end{tabular}

Tm, melting temperature. 
(fluorescent dye) and MGB (non-fluorescent quencher dye) at the $5^{\prime}$ and $3^{\prime}$ ends respectively: Hif1 $\alpha$ forward 5'-CTGTGATGAAAGAATTACTGAGTTGATG-3', Hif1 $\alpha$ reverse $5^{\prime}$ CATAAATTGAGCGGCCCAAA-3', Hif1 $\alpha$ probe $5^{\prime}$-TATGAGCCAGAAGAAC-3'; Tgf $\beta r 3$ forward 5'-CAGGACCAGCTCGATGGAA-3', Tgf $\beta r 3$ reverse 5'-CACCAGGAAGAGGTCTGTTGTTATACA-3', Tgf $\beta r 3$ probe 5'-CATCACCTTCAACATGG-3'; Serpine1 forward 5'-CTCACCAGCATCTTGGATGCT-3', Serpine 1 reverse: 5'-CGAGGCAGTCTGGTCATGTTC-3', Serpine1 probe 5'-CTCATCCGACAATGGAA-3'; Tnf forward 5'-CCCCAAAGGGAGAGAAGT- ${ }^{\prime}{ }^{\prime}$, Tnf reverse 5'-GCCATGGAGCCGTGATG-3', Tnf probe 5'-CCCAACAACCTCC-3'. A TaqMan 18S Ribosomal RNA primer and probe set (labeled with VIC (fluoresent dye); Applied Biosystems) was used as the control gene for relative quantification. Ninety-six-well PCR plates were composed of duplicate or triplicate wells for all five genes of each individual sample. On each plate, batches of samples were randomized for photoperiod treatment and time point, and sample identification was encoded to eliminate potential experimental bias. Amplification was performed on an $\mathrm{ABI}$ 7000 Sequencing Detection System by using TaqMan Universal PCR Master Mix. The universal two-step RT-PCR cycling conditions used were: $50^{\circ} \mathrm{C}$ for $2 \mathrm{~min}, 95^{\circ} \mathrm{C}$ for $10 \mathrm{~min}$, followed by 40 cycles of $95^{\circ} \mathrm{C}$ for $15 \mathrm{~s}$ and $60^{\circ} \mathrm{C}$ for $1 \mathrm{~min}$. Relative gene expression was calculated by comparison to a relative standard curve consisting of serial dilutions of pooled P. leucopus cDNA (1, 1:10, 1:100, $1: 1000)$ followed by normalization to $18 S$ rRNA gene expression.

\section{Statistical analysis}

ANOVA repeated measure tests were used to compare all repeated measures among time points. Two-tailed Student's $t$-tests compared treatment groups of interest. Data with unequal variances were log transformed and compared by ANOVA (within-week comparisons for PCR data) or compared using the non-parametric KruskalWallis test (between-week comparisons for PCR data). All comparisons were considered significant when $P<0.05$. StatView software was used for all analyses (Cary, NC, USA).

\section{Results \\ Body mass}

SDR mice weighed less than LD mice after 10, 12, 14 and 17 weeks of photoperiod treatment (Fig. $1 ; P<0.05$ in all cases). SDR mice also weighed less than SDNR mice after $2,4,10,12$ and 14 weeks of photoperiod treatment (Fig. $1 ; P<0.05$ in all cases).

\section{Estimated testicular volume}

SDR mice displayed decreased ETV as compared with LD mice after $6,8,10,12,14,17,19,21$ and 29 weeks of

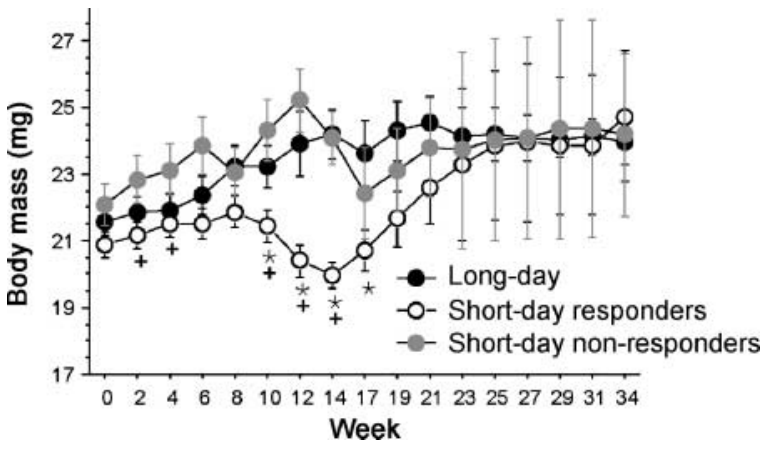

Figure 1 Effect of photoperiod treatment on body mass (means \pm S.E.M.). Weeks $0-7: \mathrm{LD}(n=38)$, SDR $(n=53)$, SDNR $(n=28)$. Weeks $8-14:$ LD $(n=29)$, SDR $(n=43)$, SDNR $(n=19)$.Weeks 15-21: LD $(n=11)$, SDR $(n=9), \operatorname{SDNR}(n=8)$. Weeks 22-34: LD $(n=4)$, SDR $(n=4)$, SDNR $(n=4) .{ }^{*}, P<0.05$ between LD and SDR;,$+ P<0.05$ between SDR and SDNR.

photoperiod treatment (Fig. $2 ; P<0.05$ in all cases). SDR mice displayed decreased ETV as compared with SDNR mice after $0,6,8,10,12,14,17,19,21$ and 23 weeks of photoperiod treatment (Fig. 2; $P<0.05$ in all cases).

\section{Tissue masses}

Secondary reproductive tissue absolute masses and masses relative to body mass (absolute mass/body mass $\times 1000$ ) are shown in Table 2. Testes and epididymides absolute masses decreased in SDR mice as compared with LD mice after 7, 14 and 21 weeks of photoperiod treatment, whereas absolute seminal vesicles mass decreased after 7 , 14, 21 and 34 weeks ( $P<0.05$ in all cases). Calculation of masses of these tissues after adjusting for body mass yielded similar statistically significant differences except for epididymides mass at 7 weeks and testes mass at 14 weeks (see Table 2; $P<0.05$ ). Absolute and relative epididymal fat pad mass also decreased in SDR mice as compared with LD mice, but only after 14 weeks of treatment

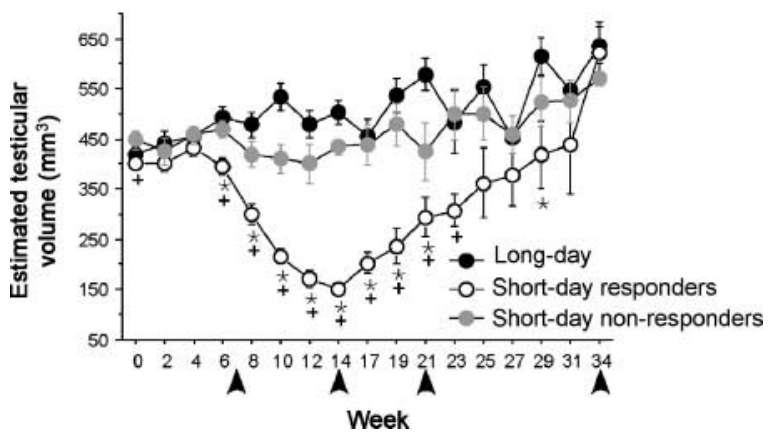

Figure 2 Effect of photoperiod treatment on reproductive status (means \pm S.E.M.). Weeks 0-7: LD $(n=38)$, SDR $(n=53)$, SDNR $(n=28)$. Weeks 8-14: LD $(n=29)$, SDR $(n=43)$, SDNR $(n=19)$. Weeks 15-21: LD $(n=11)$, SDR $(n=9)$, SDNR $(n=8)$. Weeks 22-34: LD $(n=4)$, SDR $(n=4)$, SDNR $(n=4) .{ }^{*}, P<0.05$ between LD and SDR;,$+ P<0.05$ between SDR and SDNR. Time points of tissue collections are indicated by arrow-heads. 


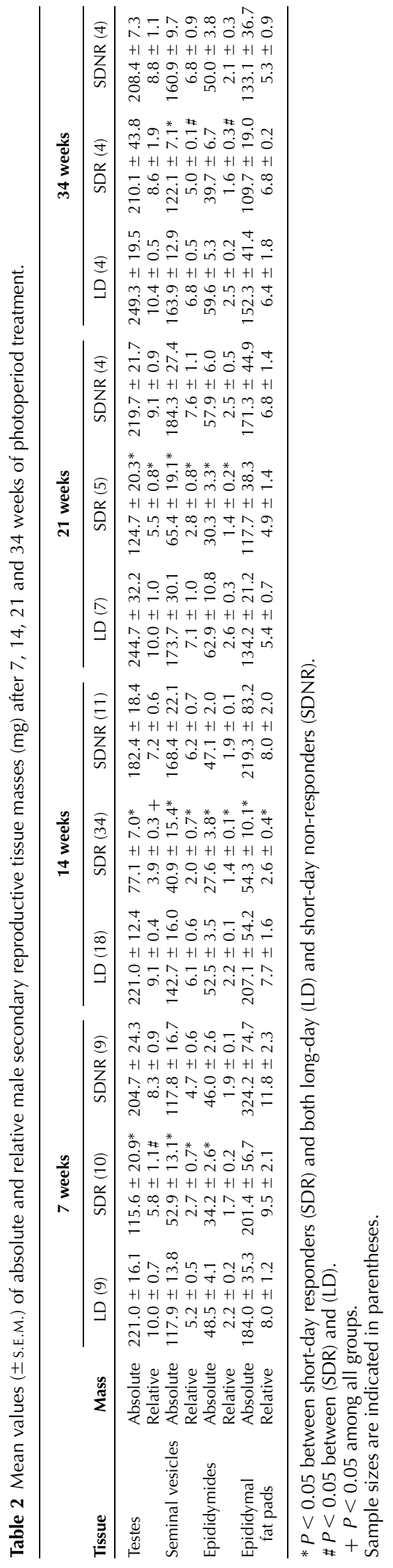

$(P<0.05)$. Additionally, relative seminal vesicles and epididymides masses were decreased in SDR mice after 34 weeks as compared with LD mice $(P<0.05)$. Both absolute and relative testes and epididymides masses of SDR mice also decreased as compared with SDNR mice after 7,14 and 21 weeks of photoperiod treatment $(P<0.05$ in all cases). Absolute seminal vesicle mass also decreased in SDR as compared with SDNR at all time points $(P<0.05$ in all comparisons). Both absolute and relative epididymal fat pad mass decreased in SDR mice as compared with SDNR mice, but only after 14 weeks of treatment $(P<0.05)$.

\section{Histology}

Average seminiferous tubule diameters decreased in SDR mice after 7 and 14 weeks of photoperiod treatment as compared with LD mice (Fig. 3A-D; $P<0.05$ for both time points). SDR mice had significantly reduced seminiferous tubule diameters as compared with SDNR mice at 14 weeks (Fig. 3A-D; $P<0.05$ ). Tubule diameter did not differ between LD and SDNR mice at any time point ( $P>0.05$ in all cases). Additionally, stained nuclei found in the centre of seminiferous tubules of LD and SDNR mice depicted active spermatogenesis in these groups (Fig. 3B and D).

\section{Microarrays}

Microarray expression differences of at least 2-fold are summarized in Table 3. Based on the distribution of the fold differences, genes with $\geq 6$-fold differences among photoperiod treatments were examined throughout testicular regression and recrudescence using qPCR.

\section{qRT-PCR}

All gene expression data were log transformed due to unequal variances. Relative gene expression of Hif1 $\alpha$, $T g f \beta r 3$, Serpine 1 and Tnf was increased in all SD mice at week 7 as compared with LD mice (Fig. 4A-D; $P<0.05$ ). At week 14, only SDR mice had increased Hif1 $\alpha, \operatorname{Tgf} \beta r 3$ and Tnf gene expression (Fig. 4A, B and D; $P<0.05$ ), whereas expression levels of SDNR mice were similar to LD mice $(P>0.05)$. However, the Serpine1 gene expression relationship among photoperiod groups reversed at 14 weeks such that expression in LD mice was numerically higher than in SDNR mice, although this difference was not statistically significant (Fig. 4C; $P=0.17$ ). At week 21, this increase in Serpine1 expression in LD mice was significantly greater than all SD mice (Fig. 4C; $P<0.05$ ). Also at week 21 , SDR mice maintained their heightened expression level of Tnf, although it was only significantly higher than SDNR mice (Fig. 4D; $P<0.05$ ). SDR and LD mice had similar Tgf $\beta r 3$ expression levels by week 21, although the SDNR level was significantly decreased (Fig. 4B; $P<0.05$ ). Finally, LD mice displayed an increase in $\operatorname{Tgf} \beta r 3$ expression after 


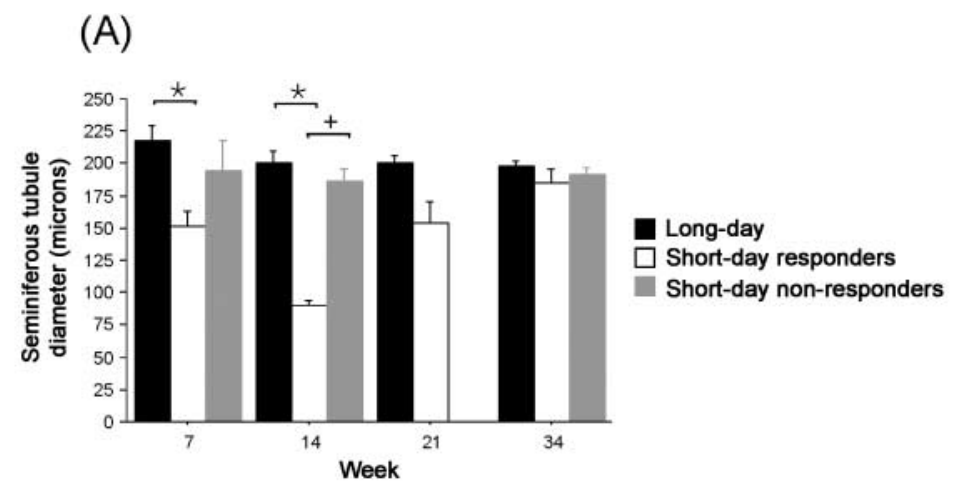

(B)

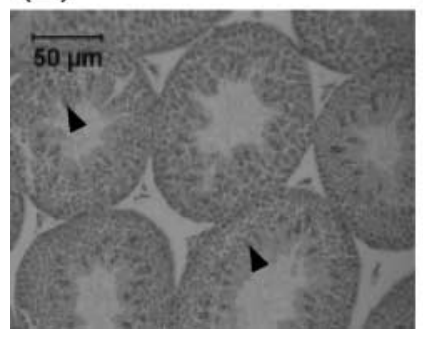

(C)

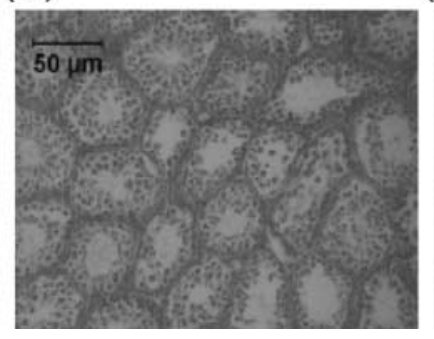

(D)

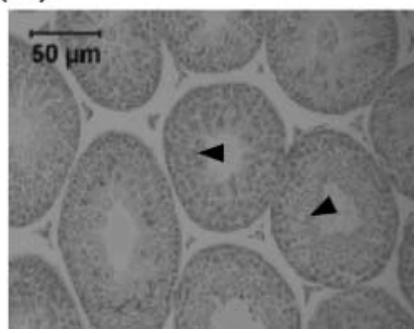

Figure 3 Influence of 14 weeks of photoperiod treatment on seminiferous tubule diameter in testes (A) (means \pm S.E.M.). $*, P<0.05$ between LD and SDR mice; + , $P<0.05$ between SDR and SDNR mice. Representative morphology of seminiferous tubules in LD (B), SDR (C) and SDNR (D) mice. LD, $n=6 ; \mathrm{SDR}, n=8 ; \mathrm{SDNR}, n=6$. Arrow-heads indicate stained spermatocyte nuclei.
34 weeks of photoperiod treatment (Fig. 4B; $P<0.05$ ). No differences in Hif1 $\alpha$, Serpine1 or Tnf expression existed among groups at 34 weeks (Fig. 4A, C and D; $P>0.05$ ).

There were significant effects of week on Tgf $\beta r 3$, Serpine1 and Tnf expression in LD, SDR and SDNR mice $(P<0.05$ in all cases). Additionally, there was a significant effect of week on Hif1 $\alpha$ expression in LD only $(P<0.05)$.

\section{Discussion}

The present study confirms and extends previous results that short days decrease reproductive tract mass, body mass and seminiferous tubule diameter in adult male white-footed mice (Whitaker 1940, Johnston \& Zucker 1980, Glass 1986). Additionally, expression of genes involved in angiogenesis differs in testes of LD and SD mice and corresponds to the photoperiod-driven pattern of regression/recrudescence of the reproductive tract. Specifically, SD mice display high expression levels of Hif1 $\alpha$, Tgf $\beta r 3$ and Serpine1 during testicular regression and high expression levels of Tnf during testicular recrudescence. These data are consistent with the hypothesis that photoperiod alters expression of angiogenesis genes in adult males.

Angiogenesis in adult mammals has been studied in the context of tumour growth, wound healing and the cyclical changes of the female reproductive tract. Studies of angiogenesis specific to adult males are sparse and are limited to models of seasonal breeders including dormice (G. glis), ferrets (M. furo), and foxes (V. vulpes) (Joffre \& Joffre 1973). Dormice and foxes increase capillary blood flow in the testes during the breeding season. Short days decrease blood vessel volume and transfer to long days increases vascular permeability in the testes of Syrian hamsters

Table 3 Two fold or greater angiogenesis gene expression differences in the testes after 14 weeks of photoperiod treatment.

\begin{tabular}{|c|c|c|c|c|c|c|}
\hline \multirow[b]{2}{*}{ Gene } & \multicolumn{3}{|c|}{14 weeks } & \multirow[b]{2}{*}{ Fold difference } & \multirow[b]{2}{*}{ RT-PCR } & \multirow[b]{2}{*}{ Function } \\
\hline & LD & SDR & SDNR & & & \\
\hline Angiopoietin 2 & & $\uparrow$ & & 2 & & Vessel remodeling and sprouting \\
\hline Hypoxia-inducible factor $1 \alpha(H i f 1 \alpha)$ & & $\uparrow$ & & 19.4 & * & Pro-angiogenic or pro-apoptotic \\
\hline Endothelial nitric oxide synthase & $\uparrow$ & & & 5.1 & & Vessel permeability \\
\hline Plasminogen activator inhibitor 1 (Serpine1) & $\uparrow$ & & & 6.4 & * & Matrix remodeling; pro- or anti-angiogenic \\
\hline Secreted acidic cysteine-rich glycoprotein & $\downarrow$ & & & 4.2 & & Cell detachment, matrix remodeling \\
\hline TGF $\beta$ receptor 3 (Tgf $\beta r 3)$ & & $\uparrow$ & & 69.4 & * & Inhibit formation of new vessels by TGF $\beta$ \\
\hline Tenascin C & & $\uparrow$ & & 5.5 & & Cell adhesion and detachment \\
\hline Tumor necrosis factor $(T n f)$ & & $\uparrow$ & & 20.9 & $*$ & Differentiate cells to support new vessels \\
\hline
\end{tabular}

Fold difference expression difference between LD and SDR at 14 weeks.

* Examination of gene expression by RT-PCR. 

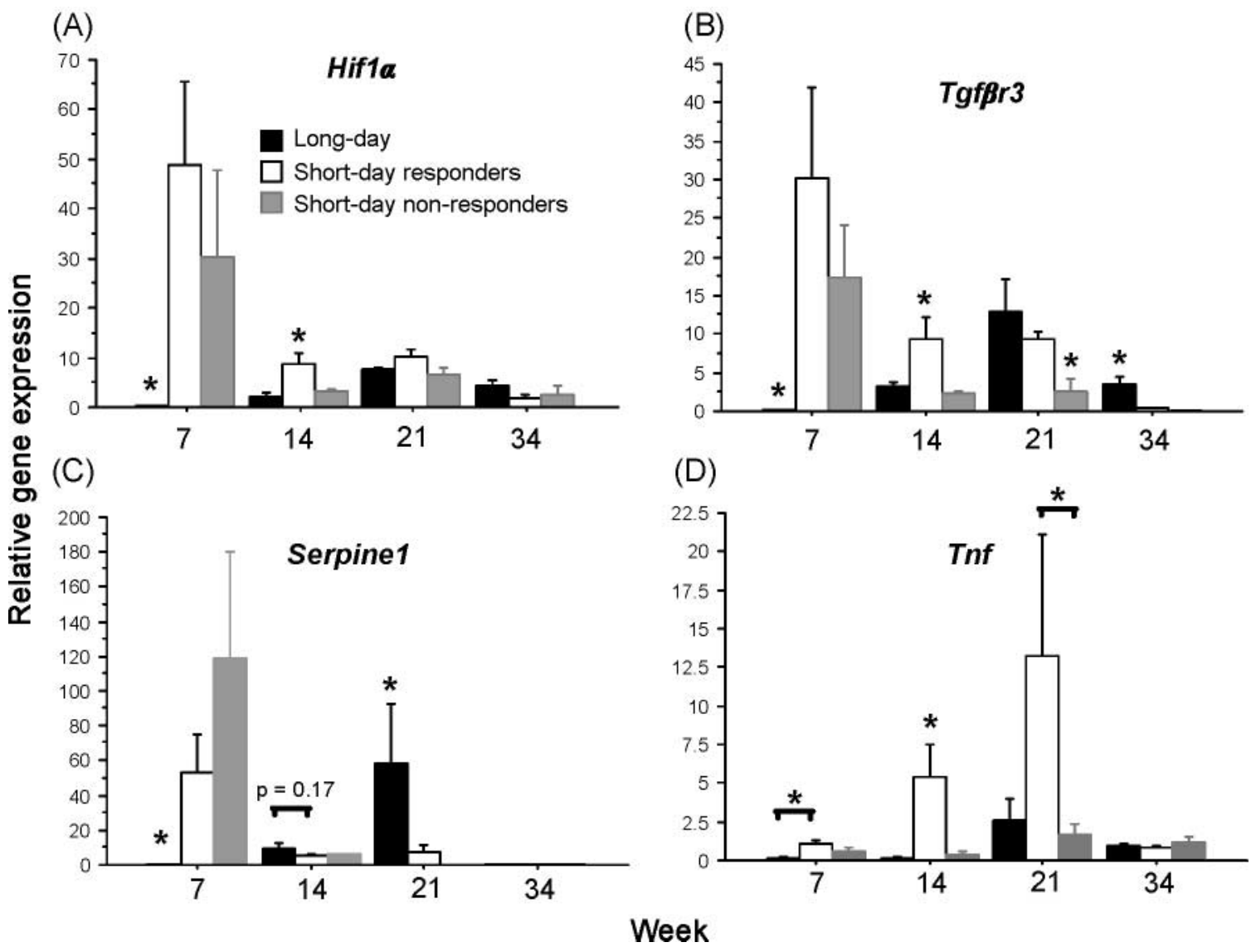

Figure 4 Effect of 7, 14, 21 and 34 weeks of photoperiod treatment on Hif1 $\alpha$ (A), Tgfßr3 (B), Serpine1 (C) and Tnf (D) gene expression relative to $18 S$ rRNA expression in the testes. ${ }^{*}, P<0.05$ among all photoperiod groups of a single time point unless specified by a bar. $n=4$ per photoperiod group per time point.

(M. auratus) (Mayerhofer et al. 1989). Similarly, testicular blood vessel volume of adult male red stags (Cervis elaphus) and camels (Camelus dromedaries) was greater when measured in the breeding season than during the non-breeding season (Hochereau-de Reviers \& Lincoln 1978, Zayed et al. 1995). In mink (Mustela vison), the blood-testis barrier competency changes across seasons, although the pattern of competency does not completely match the seasonal progression of spermatogenesis (Pelletier 1986). These studies provide evidence for structural changes in the testicular vasculature of seasonally breeding adult males.

The mechanisms by which testicular vasculature varies across seasons have not been established. However, Vegf may be implicated in this process based on the positive relationship between VEGF protein expression and testes mass in SD and LD white-footed mice (Young \& Nelson 2000). No differences ( $\geq 2$-fold) in Vegf gene expression were found in this study. However, the time points at which gene expression were assessed are 'snapshots' of a 34-week process of regression and recrudescence. It is possible that the differential gene expression necessary for morphological changes in the testes was relatively transient, and therefore missed by our sampling schedule.
Additionally, gene transcription and translation of gene products may not overlap in time, and therefore, VEGF protein expression may be high at particular time points whereas, Vegf transcription may have already returned to basal levels. Studies using models in which more abrupt changes in testes mass are measured are necessary to examine changes in angiogenesis gene expression over a more concentrated window of time. Our study implicates several other genes in the process of seasonal angiogenesis of the testes.

Directed by our preliminary microarray findings after 14 weeks of photoperiod treatment (the nadir of testicular regression), we investigated expression patterns of four genes involved in angiogenesis. Hif1 $\alpha$ is an oxygen-regulated subunit of the HIF transcription factor that has been implicated in both angiogenesis and apoptosis (Piret et al. 2002). The overlap of the timing of testicular apoptosis in SD white-footed mice and the expression pattern of Hif1 $\alpha$ suggests that expression of Hif1 $\alpha$ in SD mice may be an indicator of apoptosis associated with testicular regression (Young et al. 2001). Tgf $\beta r 3$, also known as betaglycan, in its soluble form, is a potent antagonist of TGF $\beta$, a promoter of angiogenesis. Additionally, expression of the soluble extracellular domain of $\mathrm{TGF} \beta \mathrm{r} 3$ inhibits angiogenesis 
in vivo and in vitro (Bandyopadhyay et al. 2002). Therefore, it is likely that the initial increase in $T g f \beta r 3$ expression in SD mice represents an inhibition of testicular angiogenesis. The effect of Serpine1 on tumour growth and angiogenesis depends on the level of expression. High SERPINE1 doses inhibit tumour growth and angiogenesis in vivo, whereas, low doses increase angiogenesis (McMahon et al. 2001). Consistent with this bi-modal function of SERPINE1, SD mice display high expression levels of Serpine1 at week 7 during regression, which suggests an inhibitory role of Serpine1 on angiogenesis. Lastly, Tnf promotes proliferation and differentiation of mesenchymal cells into pericytes or smooth muscle cells that support newly formed vessels during angiogenesis (Distler et al. 2003). The late increase in Tnf in SD testes suggests that Tnf may promote new vessel stabilization during testicular recrudescence. Overall, the timing of the expression of these four genes in SDR mice suggests that Hif1 $\alpha$, Tgf $\beta r 3$ and Serpine1 are involved in testicular regression, whereas Tnf is involved in testicular recrudescence.

The effect of time (weeks) on gene expression in LD testes was unexpected. We predicted that the vasculature in LD animals would be stable. However, many genes (including the ones examined in the present study) have multiple functions and it is possible that the changes measured in LD testes may be associated with extra-angiogenic processes. Alternatively, the trend of increasing gene expression peaking around week 21 in LD mice may be due to a fluctuation in overall body growth (including the testes). Between 14 and 21 weeks, the LD animals display a slight drop in body mass followed by a recovery that may account for slight changes in testicular gene expression at this time.

In this study, microarrays designed for Mus musculus were used for $P$. leucopus which may have resulted in false positive and negative findings based on possible sequence differences between the species. Therefore, the microarray analysis was solely used as a screening procedure whereas the specificity and sensitivity of $\mathrm{qPCR}$ enabled precise examination of specific genes of interest. Common laboratory animals that have been selectively bred to ignore seasonal cues - such as M. musculus and Rattus norvegicus - and for which molecular tools are readily available, are not suitable for this type of comparative study. Because of the genomic homology among species, however, it is possible to work around some of the molecular roadblocks to address ecologically relevant questions in genetically heterogeneous populations.

The SDNR group represents the population of mice that fails to regress their gonads in response to short day lengths. This population is not merely a laboratory anomaly because winter breeding has been reported in field studies and is thought to confer fitness advantages during mild winters (Prendergast et al. 2001). We compared the SDNR animals to the LD and SDR phenotypes. Body mass, testes size and testes morphology of the SDNR group were more similar to LD than to SD mice. With respect to gene expression of our four candidate genes, the SDNR profile initially (Fig. 4A-D; week 7) was similar to that of the SDR group. However, by week 14, SDNR expression of all four genes switched to resemble that of the LD mice. These data suggest that there is some breakdown between the transcription of the gene and the function of the gene product. Potential differences between SDNR and SDR post-transcriptional pathways may exist. However, in SDNR mice the uncoupling between large, sperm-filled testes (characteristic of LD animals) and their initial SDR-like gene expression profile suggests that testosterone is not the only factor influencing angiogenesis gene expression in the testes. Additionally, long durations of melatonin secretion do not appear sufficient to induce SDR-like angiogenesis expression profiles in the testes because SDNR and SDR white-footed mice display the same long melatonin durations (Carlson et al. 1989) but different gene expression patterns.

The present study is among the first to describe seasonal plasticity of angiogenesis in adult testes on a molecular level. Changes in angiogenesis gene expression differ between testes of LD and SD white-footed mice and correspond to changes in testicular morphology. The gene expression profile of SDNR mice initially resembled that of SDR mice, but subsequently became similar to LD mice. Future studies are necessary to determine the intervening role of testosterone and melatonin in photoperiodinduced changes in testicular angiogenesis gene expression. It is likely that seasonal melatonin secretion exerts its effects on testicular angiogenesis via an indirect central mechanism that may implicate testosterone. Melatonin receptors have not been localized in the testes in this species and melatonin does not affect testosterone secretion from testicular cells in vitro (Knotts et al. 1988). However, binding of melatonin to receptors in the hypothalamus does modulate reproductive hormone secretion (Glass \& Dolan 1988). Therefore, melatonin-induced changes in testosterone secretion may regulate seasonal angiogenesis (or possibly gonadotrophin-releasing hormone $(\mathrm{GnRH})$, luteinizing hormone $(\mathrm{LH})$, follicle-stimulating hormone $(\mathrm{FSH})$ or some combination of these peptides). Because non-pathological angiogenesis in adults is rare (particularly in males) understanding the mechanisms underlying this model of seasonal angiogenesis may prove to have therapeutic value.

\section{Acknowledgements}

We thank Tina VanMeter and Brenda Reader for their technical assistance. Supported by NIH grant MH57535.

\section{References}

Bandyopadhyay A, Zhu Y, Malik SN, Kreisberg J, Brattain MG, Sprague EA, Luo J, Lopez-Casillas F \& Sun LZ 2002 Extracellular domain of TGFbeta type III receptor inhibits angiogenesis and tumor growth in human cancer cells. Oncogene 21 3541-3551. 
Brem S 1976 The role of vascular proliferation in the growth of brain tumors. Clinical Neurosurgery 23 440-453.

Bronson FH 1985 Mammalian reproduction: an ecological perspective. Biology of Reproduction 32 1-26.

Carlson LL, Zimmermann A \& Lynch GR 1989 Geographic differences for delay of sexual maturation in Peromyscus leucopus: effects of photoperiod, pinealectomy, and melatonin. Biology of Reproduction 41 1004-1013.

Distler JH, Hirth A, Kurowska-Stolarska M, Gay RE, Gay S \& Distler O 2003 Angiogenic and angiostatic factors in the molecular control of angiogenesis. Quarterly Journal of Nuclear Medicine 47 149-161.

Glass JD 1986 Short photoperiod-induced gonadal regression: effects on the gonadotropin-releasing hormone $(\mathrm{GnRH})$ neuronal system of the white-footed mouse. Peromyscus leucopus. Biology of Reproduction 35 733-743.

Glass JD \& Dolan PL 1988 Melatonin acts in the brain to mediate seasonal steroid inhibition of luteinizing hormone secretion in the white-footed mouse (Peromyscus leucopus). Proceedings of the Society for Experimental Biology and Medicine $188375-380$.

Goldman BD 2001 Mammalian photoperiodic system: formal properties and neuroendocrine mechanisms of photoperiodic time measurement. Journal of Biological Rhythms 16 283-301.

Gorman MR \& Zucker I 1995 Seasonal adaptations of Siberian hamsters. II. Pattern of change in daylength controls annual testicular and body weight rhythms. Biology of Reproduction $\mathbf{5 3}$ 116-125.

Gram WD, Heath HW, Wichman HA \& Lynch GR 1982 Geographic variation in Peromyscus leucopus: short-day induced reproductive regression and spontaneous recrudescence. Biology of Reproduction 27 369-373.

Hochereau-de Reviers MT \& Lincoln GA 1978 Seasonal variation in the histology of the testis of the red deer, Cervus elaphus. Journal of Reproduction and Fertility 54 209-213.

Joffre J \& Joffre M 1973 Seasonal changes in the testicular blood flow of seasonally breeding mammals: dormouse, Glis glis, ferret, Mustella furo, and fox, Vulpes vulpes. Journal of Reproduction and Fertility 34 227-233.

Johnston PG \& Zucker I 1980 Photoperiodic regulation of the testes of adult white-footed mice (Peromyscus leucopus). Biology of Reproduction 23 859-866.

Klagsbrun M \& Moses MA 1999 Molecular angiogenesis. Chemistry and Biology 6 R217-R224.

Knotts LK, Bruot BC \& Glass JD 1988 Melatonin does not affect in vitro secretion of testosterone in white-footed mouse testis. Journal of Pineal Research 5 521-526.

Lynch GR, Heath HW \& Johnston CM 1981 Effect of geographical origin on the photoperiodic control of reproduction in the whitefooted mouse, Peromyscus leucopus. Biology of Reproduction $\mathbf{2 5}$ 475-480.

McMahon GA, Petitclerc E, Stefansson S, Smith E, Wong MK, Westrick RJ, Ginsburg D, Brooks PC \& Lawrence DA 2001 Plasminogen activator inhibitor-1 regulates tumor growth and angiogenesis. Journal of Biological Chemistry 276 33964-33968.
Mayerhofer A, Sinha Hikim AP, Bartke A \& Russell LD 1989 Changes in the testicular microvasculature during photoperiod-related seasonal transition from reproductive quiescence to reproductive activity in the adult golden hamster. Anatomical Record $\mathbf{2 2 4}$ 495-507.

Nelson RJ, Demas GE, Klein SL \& Kriegsfeld LJ 2002 Seasonal patterns of stress, immune function, and disease, edn 1: New York, USA Cambridge University Press.

Neufeld G, Cohen T, Gengrinovitch S \& Poltorak Z 1999 Vascular endothelial growth factor (VEGF) and its receptors. FASEB Journal 13 9-22.

Pelletier RM 1986 Cyclic formation and decay of the blood-testis barrier in the mink (Mustela vison), a seasonal breeder. American Journal of Anatomy 175 91-117.

Piret JP, Mottet D, Raes M \& Michiels C 2002 Is HIF-1alpha a pro- or an anti-apoptotic protein? Biochemical Pharmacology 64 889-892.

Prendergast BJ \& Nelson RJ 2001 Spontaneous 'regression' of enhanced immune function in a photoperiodic rodent Peromyscus maniculatus. Proceedings of the Royal Society of London B. Biological Sciences $2682221-2228$.

Prendergast BJ, Kriegsfeld LJ \& Nelson RJ 2001 Photoperiodic polyphenisms in rodents: neuroendocrine mechanisms, costs, and functions. Quaterly Review of Biology 76 293-325.

Smale L, Dark J \& Zucker I 1988 Pineal and photoperiodic influences on fat deposition, pelage, and testicular activity in male meadow voles. Journal of Biological Rhythms 3 349-355.

Smith SK 2001 Angiogenesis and reproduction. BJOG 108 777-783.

Tomanek RJ \& Schatteman GC 2000 Angiogenesis: new insights and therapeutic potential. Anatomical Record 261 126-135.

Whitaker W 1940 Some effects of artificial illumination on the reproduction in the white-footed mouse, P. leucopus noveboracensis. Journal of Experimental Zoology 83 33-60.

Young KA \& Nelson RJ 2000 Short photoperiods reduce vascular endothelial growth factor in the testes of Peromyscus leucopus. American Journal of Physiology. Regulatory, Integrative and Comparative Physiology 279 R1132-R1137.

Young KA \& Nelson RJ 2001 Mediation of seasonal testicular regression by apoptosis. Reproduction 122 677-685.

Young KA, Zirkin BR \& Nelson RJ 2000 Testicular regression in response to food restriction and short photoperiod in white-footed mice (Peromyscus leucopus) is mediated by apoptosis. Biology of Reproduction 62 347-354.

Young KA, Zirkin BR \& Nelson RJ 2001 Testicular apoptosis is downregulated during spontaneous recrudescence in white-footed mice (Peromyscus leucopus). Journal of Biological Rhythms 16 479-488.

Zayed AE, Hifny A, Abou-Elmagd A \& Wrobel KH 1995 Seasonal changes in the intertubular tissue of the camel testis (Camelus dromedarius). Anatomischer Anzeiger 177 199-212.

Received 3 August 2004

First decision 8 October 2004

Revised manuscript received 13 October 2004

Accepted 19 October 2004 